\title{
Dinâmica da onda folicular na aplicação dos hormônios utilizados em protocolos de IATF: Revisão
}

\author{
Dayane Priscila Vrisman ${ }^{1}$, Marlon Richard Hilário da Silva ${ }^{2}$. \\ ${ }^{1}$ Médica Veterinária, Residente em Reprodução Animal pela Universidade Estadual do Centro-Oeste, campus \\ CEDETEG, Departamento de Medicina Veterinária. Guarapuava, Paraná. [dayvrisman@ @otmail.com] \\ ${ }^{2}$ Médico Veterinário, Professor do Curso de Medicina Veterinária da Universidade Estadual do Centro-Oeste - \\ UNICENTRO, Guarapuava-PR.
}

ISSUE DOI: $10.3738 / 1982.2278 .1128$

A eficiência reprodutiva é um dos fatores que mais influenciam o sucesso econômico de um sistema de produção, e está diretamente relacionada ao retorno da ciclicidade no pós-parto, ao intervalo entre partos e primeira inseminação e ao intervalo parto-concepção. Utilizando-se a Inseminação Artificial em Tempo Fixo (IATF) adequadamente, pode-se concentrar um maior número de vacas com um intervalo entre partos ideal de 12 meses. Um exemplo de protocolo de IATF realizado é: no primeiro dia (D0), introdução via vaginal de um implante de progesterona (P4), juntamente com 2mg/animal de benzoato de estradiol (BE). No D7 é aplicado 150 $\mu \mathrm{g} /$ animal de D-cloprostenol (Prostaglandina 2-alfa sintética, PGF2 $\alpha$ ); no D8, o implante de progesterona é retirado e aplicado $1 \mathrm{mg}$ /animal de cipionato de estradiol (ECP). No D10 é feita a IATF de todos animais que participaram do tratamento. A associação de progesterona com estrógeno no D0 promove a atresia dos folículos dominante e subordinados. A atresia do dominante ocorre devido a P4, a qual permanecendo em elevadas concentrações plasmáticas proporciona uma redução na secreção do GnRH. Como consequência o LH terá um padrão de secreção em baixa frequência e amplitude, não permitindo a ovulação do folículo dominante, mas sim a sua atresia. Já a atresia dos folículos subordinados ocorre devido a aplicação do BE. O estrógeno em maior concentração provoca uma diminuição na liberação de FSH. Em baixas concentrações, os folículos subordinados não continuam seu desenvolvimento e sofrem atresia. A retirada do P4 reduz os níveis de progesterona no organismo do animal. Isso determina uma redução do bloqueio ao $\mathrm{GnRH}$, e uma maior produção deste hormônio estimula o crescimento e a maturação folicular, culminando com o cio sincronizado. A aplicação de PGF2 $\alpha$ pode ser realizado em até um dia antes da retirada do $\mathrm{P} 4$, pois os níveis sanguíneos da prostaglandina demoram a cair em até 24 horas. Após a retirada do P4, os níveis desse hormônio diminuem na corrente sanguínea em até 12 horas. Por isso a PGF2 $\alpha$ pode ser aplicada em até um dia antes da retirada do P4. A aplicação do ECP tem o objetivo de sincronizar a ovulação. Isso ocorre devido ao estímulo na liberação de GnRH, o qual por sua vez estimula a liberação do FSH e LH, hormônios responsáveis pelo 
crescimento final do folículo dominante e posterior ovulação. A inseminação dos animais submetidos ao protocolo de IATF é realizada dois dias após a aplicação do ECP. Não há dúvidas que a IATF pode acrescentar em muito a produção pecuária atual, melhorando as taxas de prenhez, o ganho genético e elevando as taxas de desfrute e a produtividade do rebanho.

Palavras-chave: atresia folicular, benzoato de estradiol, eficiência reprodutiva, implante de progesterona, prostaglandina. 